\title{
ALCOHOL CONSUMPTION AND MARIJUANA USE IN YOUNG ADULT CZECHS
}

\author{
Ladislav Csémy ${ }^{1,2}$, Hana Sovinová1, Bohumír Procházka ${ }^{1}$ \\ ${ }^{1}$ National Institute of Public Health, Prague, Czech Republic \\ ${ }^{2}$ Prague Psychiatric Centre, Prague, Czech Republic
}

\begin{abstract}
SUMMARY
Objectives: The main objective of the study is to explore associations between alcohol consumption and marijuana use in young adults and to discuss the opportunities for brief intervention.

Methods: Face to face structured interviews were carried out with 2,221 young adult Czechs (mean age 29.9, sd. 5.8 years). 51.4\% were males. Alcohol consumption was calculated using beverage specific quantity frequency method. Alcohol-related problems were assessed using the Czech version of the AUDIT. Frequency of marijuana use in the last twelve months was asked as well.

Results: The overall alcohol consumption was 9.2 litres of pure alcohol per person and year. The last year prevalence of marijuana use was $21.8 \%$. The use of marijuana positively correlated with the frequency of beer drinking ( $r=0.27)$, frequency of heavy episodic drinking [HED] $(r=0.32)$ and with the summary score in AUDIT ( $r=0.39$ ). Harmful or problem drinkers (AUDIT score $\geq 16$ ) reported marijuana use more frequently than moderate drinkers ( $60 \%$ compared to $18.8 \% ; \mathrm{OR}=6.54 ; 95 \% \mathrm{Cl}=4.7 ; 9.1)$. OR for marihuana use in heavy episodic drinkers was $4.3(95 \% \mathrm{Cl}=3.3 ; 5.6)$.

Discussion: The results suggest that frequent HED and harmful drinking are closely associated with marijuana use in younger adults. Since marijuana use (including heavy use) is rather common in the Czech Republic, it would be recommendable to also extend screening and brief intervention to reduce the use of cannabis. The existing guidelines for brief intervention should be modified in order to cover marijuana consumption as well.
\end{abstract}

Key words: alcohol consumption, marijuana use, AUDIT, young adults, Czech Republic

Address for correspondence: L. Csémy, Prague Psychiatric Centre, Ústavni 91, 18103 Praha 8, Czech Republic. E-mail: csemy@pcp.lf3.cuni.cz

\section{INTRODUCTION}

The relationship between alcohol consumption and the use of other drugs is often studied in clinical populations. Gossop et al. (2002) indicate that alcohol abuse is an important and often neglected problem in patients treated for problems caused by the use of illicit drugs (1). Petry (2001) in his study focused on analyses of prevalence of illegal drug use among alcoholics: in his sample the most commonly used substance was cocaine, followed by marijuana and benzodiazepines (2). Midanik et al. (2007) emphasized the need to address the problem of alcohol use and use of other drugs in the general population. They examined associations between drinking and other drug use in a representative sample of more than seven thousand Americans (3). Ten percent of current alcohol drinkers used marijuana within the last year and seven percent reported use of alcohol and marijuana at the same time (simultaneous use). The research results showed that concurrent use of alcohol and another drug has more adverse social and health consequences than the use of alcohol or any drug alone. In relation to alcohol and marijuana, scientific literature has repeatedly addressed the theory of substitution effect. Especially in countries with restrictive alcohol policy it was considered that the unavailability of alcohol may lead to an active search of marijuana. Most recent studies, however, conclude that the relation between alcohol and marijuana is rather complementary than substitutional $(4,5,6)$.

In this study, we focus on estimating the prevalence of alcohol and drug use among young adults and on analyses of the associations between alcohol and marijuana use.

\section{METHODS}

\section{Study Group and Sampling Strategy}

The study group included 2,221 subjects aged 18 to 39 years (mean age 29.9, s.d. 5.8). The sample was representative of the Czech population with regards to gender, age, level of education and geographic distribution. The subjects were recruited by a two-step selection process. The electoral districts were chosen in the first step. The Complex Samples module of the SPSS programme was used to perform the stepwise selection, applying a step calculated on the number of registered voters in each electoral district (the number of registered voters is the measure of size in the probability proportional to size systematic selection method), whereby the probability of inclusion was identical for each voter. The stepwise selection was performed for each administrative region independently (the administrative region was the stratification variable), whereby appropriate representation of all regions was assured. The required number of electoral districts selected in each administrative region was calculated proportionally with respect to the number of registered voters in the region. In step two, the random walk approach was used; interviewers sought respondents based on a quota system within each electoral district selected. A total of 234 trained field interviewers were involved. Data was collected in October and November 2009. From among 2,663 persons who were invited to participate, $442(16.3 \%)$ refused, mostly stating lack of time as the reason. 


\section{Research Tool}

Data was collected using a questionnaire specifically developed for this survey. The questionnaire consisted of 61 questions, some of which were broken down into sub-questions. Each respondent provided 206 pieces of data. The questionnaire as a whole was divided into four general areas. The first part asked questions regarding the respondent's consumption of alcohol and other drugs; the remaining three parts were concerned with the respondent's health, psycho-social adaptation, and demographic data including information about the respondent's family and employment.

\section{Data Collection Method}

Information was gathered during a controlled structured interview, mostly conducted in the respondents' homes. From among the 2,228 interviews accomplished, seven were finally eliminated because of a relatively large number of unanswered questions.

\section{Electronic Data File Creation}

Information in the questionnaires was edited into a programme "Statistical Analysis of Social Data". The cleaned data set was converted to a Statistical Package for Social Sciences (SPSS) file.

\section{Variables Examined}

Hazardous and harmful patterns of alcohol consumption were assessed using the AUDIT screening questionnaire $(7,8)$. Mean yearly alcohol consumption (in litres of pure ethanol) was calculated based on the typical frequency and quantity for each type of alcoholic beverage. Last year prevalence of selected types of illicit drugs was included as well.

\section{Statistical Analysis}

Data was processed by using SPSS ver. 16 software. The chisquare test was used to examine the difference in the frequency distribution, and t-test or analysis of variance was applied to test the differences between the group averages.

\section{RESULTS}

\section{Prevalence of Illicit Drugs Use}

The study examined the last year prevalence of five groups of substances (Table 1). The most widely used drug among young adults was marijuana, which was consumed by $28.7 \%$ of men and $14.6 \%$ of women over the last year. Experience with Ecstasy was admitted by $7 \%$ of respondents. For the other drugs the prevalence was significantly lower: $3.5 \%$ for methamphetamine or other amphetamines, 3\% for LSD or other hallucinogenic substances, and $0.9 \%$ for heroin. Prevalence of use of any of the studied drugs except heroin was significantly higher for men compared with women. In subsequent explored analyses we restrict the relation between alcohol consumption and marijuana use.

\section{Use of Alcohol and Marijuana by Age Groups}

The mean yearly alcohol consumption in our cohort was 9.2 litres of $100 \%$ alcohol. The consumption in the five-year difference age groups varied slightly, but the differences in the age groups were not statistically significant. Similarly, harmful or problem drinking, defined by a score of 16 or higher in the AUDIT questionnaire, did not differ significantly according to age groups. Among the variables related to alcohol, heavy episodic drinking occurred more frequently among younger adults under

Table 1. Alcohol use related variables and last year prevalence of illicit drugs use by gender

\begin{tabular}{|c|c|c|c|c|}
\hline & Males & Females & Total & $\mathbf{P}$ \\
\hline Mean alcohol consumption (litres/year) & 13.6 & 4.6 & 9.2 & $<0.01$ \\
\hline Heavy episodic drinking weekly or more often (\%) & 17.5 & 4.9 & 11.4 & $<0.01$ \\
\hline Score in AUDIT $\geq 16(\%)$ & 12.5 & 2.7 & 7.8 & $<0.001$ \\
\hline Marijuana (\%) & 28.7 & 14.6 & 21.8 & $<0.01$ \\
\hline Pervitin and/or other amphetamines (\%) & 4.8 & 2.1 & 3.5 & $<0.001$ \\
\hline Heroin and/or other opiates (\%) & 1.0 & 0.7 & 0.9 & n.s. \\
\hline LSD and/or other hallucinogens (\%) & 4.4 & 1.5 & 3.0 & $<0.001$ \\
\hline Ecstasy (\%) & 8.7 & 5.3 & 7.0 & $<0.01$ \\
\hline
\end{tabular}

n.s. - not significant

Table 2. Alcohol consumption, heavy episodic drinking, marijuana use, and score in AUDIT by age groups

\begin{tabular}{|c|c|c|c|c|c|c|}
\hline & $\begin{array}{c}\text { 18-24 years } \\
(n=485)\end{array}$ & $\begin{array}{c}25-29 \text { years } \\
(\mathrm{n}=542)\end{array}$ & $\begin{array}{c}\text { 30-34 years } \\
(\mathrm{n}=651)\end{array}$ & $\begin{array}{c}35-39 \text { years } \\
(\mathrm{n}=543)\end{array}$ & $\begin{array}{c}\text { Total sample } \\
(n=2,221)\end{array}$ & $\mathbf{P}$ \\
\hline Mean (s.d.) alcohol consumption (litres/year) & $9.9(13.1)$ & $9.3(12.9)$ & $8.4(12.2)$ & $9.6(14.3)$ & $9.2(13.1)$ & n.s. \\
\hline Heavy episodic drinking weekly or more often (\%) & 14.8 & 12.2 & 9.1 & 10.3 & 11.4 & $<0.05$ \\
\hline Marijuana use in the last year (\%) & 38.1 & 27.3 & 16.3 & 8.5 & 21.8 & $<0.001$ \\
\hline Score in AUDIT $\geq 16(\%)$ & 9.0 & 8.9 & 6.7 & 6.9 & 7.8 & n.s. \\
\hline
\end{tabular}


29 years. Marijuana use was mostly related to age. In the youngest age group, $38 \%$ of the respondents reported use of marijuana, while in the oldest group of 35-39 it was reported by only $8.5 \%$ of respondents (Table 2).

\section{Alcohol and Marijuana Use in the Group with Low and High Risk Drinking}

Subgroups with low and high risk drinking were defined according to the score in the screening questionnaire AUDIT (cutoff score $=16$ points). The mean annual consumption of alcohol was several times higher both in men and women in the high risk group. Heavy episodic drinking was 5 times more frequent among men in the high-risk group compared to the low-risk group. In women, this difference was tenfold. For both men and women, the prevalence of marijuana use was significantly higher in the high-risk group (61.6\% vs. $24.2 \%$ and $53.6 \%$ vs. $13.6 \%)$. Differences in all variables between low-risk group and high-risk group (Table 3 ) were statistically significant for men and women as well $(\mathrm{p}<0.01)$.

\section{Correlation Between Drinking of Alcoholic Bever- ages, Marijuana Use, and AUDIT Score}

Table 4 summarizes the correlation coefficients (Pearson) between the frequency of drinking alcoholic beverages, marijuana use, and the AUDIT score. The values above diagonal are for men, the values under the diagonal are for women. We found the highest correlation for men between AUDIT score and the frequency of heavy episodic drinking (0.66), followed by correlations with frequency of drinking of spirits and drinking of beer. For women, the values of correlation coefficient were somewhat lower, otherwise they differed from men only in the fact that wine drinking correlated significantly higher. Frequency of marijuana use has the closest relationship to the score in the AUDIT questionnaire $(r=0.286$ in men and 0.389 in women).

\section{DISCUSSION AND CONCLUSION}

Data analyses based on a representative sample of young adults confirmed the overall high level of alcohol consumption (mean annual alcohol consumption per capita exceeded 9 litres of pure alcohol), a high prevalence of potentially harmful forms of alcohol consumption (more than $11 \%$ of respondents reported heavy weekly episodic drinking, $8 \%$ fulfilled the criteria for harmful or problem drinking on the AUDIT screening questionnaire). These findings are consistent with results of other recent national studies $(9,10)$.

With regard to marijuana use, last year prevalence of $21.8 \%$ is consistent with results reported by the National Monitoring Centre for Drugs and Drug Addiction (11).

Marked gender differences were found in alcohol consumption and in the use of marijuana as well. Males had higher level of consumption per capita, higher rates of heavy episodic drinking and more men than women had an AUDIT score higher than 16, indicating hazardous or problem drinking. The last year prevalence of marihuana use was twice as high for men compared to women. Gender differences in alcohol consumption marijuana use suggest that males are at greater risk as regards adverse health and social consequences of substance abuse.

Mean alcohol consumption and AUDIT score had no association with age, however, heavy episodic drinking and marihuana use were more common in the youngest age category (18-24 years). Evidence for positive associations between use of marijuana and alcohol drinking was confirmed by correlation analysis and then by comparing the prevalence of use in low and high risk groups for alcohol problems. The relationship between alcohol consumption and marijuana use suggests that adverse effects may be more serious while the two substances are used concurrently or simultaneously. Synergistic effects are suggested by Ramaekers et al. (12) and Kelly et al. (13).

Table 3. Alcohol consumption, heavy episodic drinking, marijuana use in low risk (LR) and high risk (HR) group by gender

\begin{tabular}{|l|c|c|c|c|}
\hline \multirow{2}{*}{} & \multicolumn{2}{|c|}{ Males } & \multicolumn{2}{c|}{ Females } \\
\cline { 2 - 5 } & LR & HR & LR & HR \\
\hline Mean (s.d.) alcohol consumption (litres/year) & 10.4 & 34.8 & 4.1 & 28.6 \\
\hline Heavy episodic drinking weekly or more often (\%) & 11.9 & 58.0 & 4.1 & 42.9 \\
\hline Marijuana use in the last year (\%) & 24.2 & 61.6 & 13.6 & 53.6 \\
\hline
\end{tabular}

Table 4. Correlation matrix of drinking variables, marijuana use, and score in AUDIT by gender (values above the diagonalmales)

\begin{tabular}{|l|c|c|c|c|c|c|}
\hline & $\begin{array}{c}\text { Beer drinking } \\
\text { (frequency in } \\
\text { the last year) }\end{array}$ & $\begin{array}{c}\text { Wine drinking } \\
\text { (frequency in } \\
\text { the last year) }\end{array}$ & $\begin{array}{c}\text { Spirits } \\
\text { consumption } \\
\text { (frequency in } \\
\text { the last year) }\end{array}$ & $\begin{array}{c}\text { Heavy epi- } \\
\text { sodic drinking } \\
\text { (freq. in the } \\
\text { last month) }\end{array}$ & $\begin{array}{c}\text { Score in } \\
\text { AUDIT }\end{array}$ & $\begin{array}{c}\text { Marijuana use } \\
\text { (frequency in } \\
\text { the last year) }\end{array}$ \\
\hline Beer drinking (frequency in the last year) & 1 & 0.057 & $0.456^{* *}$ & $0.438^{* *}$ & $0.427^{* *}$ & $0.152^{* *}$ \\
\hline Wine drinking (frequency in the last year) & $0.283^{* *}$ & 1 & $0.223^{* *}$ & $0.113^{* *}$ & $0.082^{* *}$ & 0.046 \\
\hline Spirits consumption (frequency in the last year) & $0.423^{* *}$ & $0.345^{* *}$ & 1 & $0.478^{* *}$ & $0.446^{* *}$ & $0.127^{* *}$ \\
\hline Heavy episodic drinking (freq. in the last month & $0.309^{* *}$ & $0.330^{* *}$ & $0.432^{* *}$ & 1 & $0.665^{* *}$ & $0.205^{* *}$ \\
\hline Score in AUDIT & $0.380^{* *}$ & $0.351^{* *}$ & $0.476^{* *}$ & $0.626^{* *}$ & 1 & $0.286^{* *}$ \\
\hline Marijuana use (frequency in the last year) & $0.159^{* *}$ & 0.014 & $0.216^{* *}$ & $0.228^{* *}$ & $0.389^{* *}$ & 1 \\
\hline
\end{tabular}

${ }^{* *} \mathrm{p}<0.01$ 
The alcohol policy in the Czech Republic could be characterized as liberal rather than restrictive. The easy availability of alcohol beverages, low prices and cultural norms accepting alcohol consumption create a social milieu in which drinking behaviour in young adults is widely accepted. The national drug policy in the Czech Republic and the respective legislation distinguish between social dangerousness of cannabis compared to other illicit drugs. Penalties for cannabis-related crimes are lower compared to criminal activities associated with other illicit substances. Possession of low amount of marijuana is not defined as a criminal act and may be penalized by a fine. Decriminalization of marijuana is a general trend in drug policy in many Western European countries (but not in the USA) and this policy may at least partly explain the increasing popularity of marijuana use among young Europeans, including young Czechs.

The major conclusion of this study is that from the public health perspective it is desirable, especially among young adults, to pay attention to reducing alcohol consumption and in the same time reducing the use of cannabis. Specifically in the situation of the Czech Republic, the search for effective preventive intervention will require innovative approaches and also political support.

\section{Acknowledgements}

This work was supported by the Ministry of Health of the Czech Republic (Grant IGA MZ CR: No NS9645-4/2008) and by Grant RVO PCP 2012

\section{REFERENCES}

1. Gossop M, Marsden J, Stewart D. Dual dependence: assessment of dependence upon alcohol and illicit drugs, and the relationship of alcohol dependence among drug misusers to patterns of drinking, illicit drug use and health problems. Addiction. 2002 Feb;97(2):169-78.
2. Petry NM. A behavioral economic analysis of polydrug abuse in alcoholics: asymmetrical substitution of alcohol and cocaine. Drug Alcohol Depend. 2001 Mar 1;62(1):31-9.

3. Midanik LT, Tam TW, Weisner C. Concurrent and simultaneous drug and alcohol use: results of the 2000 National Alcohol Survey. Drug Alcohol Depend. 2007 Sep 6;90(1):72-80.

4. Pape H, Rossow I, Storvoll EE. Under double influence: assessment of simultaneous alcohol and cannabis use in general youth populations. Drug Alcohol Depend. 2009 Apr 1;101(1-2):69-73.

5. Williams J, Mahmoudi P. Economic relationship between alcohol and cannabis revisited. Econ Rec. 2004;80(248)36-48.

6. Pacula RL. Does increasing the beer tax reduce marijuana consumption? J Health Econ. 1998 Oct;17(5):557-85.

7. Babor TF, Higgins-Biddle CJ. Short-term interventions in risky and noxious drinking: manual for application in primary care. 2nd ed. Prague: National Institute of Public Health; 2010. (In Czech.)

8. Sovinová H, Csémy L. The Czech AUDIT: internal consistency, latent structure and identification of risky alcohol consumption. Cent Eur J Public Health. 2010 Sep;18(3):127-31.

9. Kubička L, Csémy L. An analysis of the sociodemographic context of alcohol use in the Czech adult population from the health perspective. Cas Lek Ces. 2004;143(7):435-9.

10. Sovinová H, Csémy L. Cigarette smoking and alcohol consumption in the Czech Republic. Prague: National Institute of Public Health; 2003. (In Czech.)

11. Mravčík V, Pešek R, Horáková M, Nečas V, Chomynová P, Št’astná L, et al. Annual report on the state of affairs relating to narcotics in the Czech Republic in 2010. Prague: Office of the Government of the Czech Republic; 2011. (In Czech.)

12. Ramaekers JG, Berghaus G, van Laar M, Drummer OH. Dose related risk of motor vehicle crashes after cannabis use. Drug Alcohol Depend. 2004 Feb 7;73(2):109-19.

13. Kelly E, Darke S, Ross J. A review of drug use and driving: epidemiology, impairment, risk factors and risk perceptions. Drug Alcohol Rev. 2004 Sep;23(3):319-44. 